\title{
Estimation of Superficial Venous Reflux with Duplex Ultrasound and Foot Volumetry
}

\author{
Helene Zachrisson ${ }^{1 *}$, Oskar Nelzén ${ }^{2}$, Claes Lassvik ${ }^{1}$ and Johan Skoog ${ }^{3}$ \\ ${ }^{1}$ Department of Clinical Physiology, Medical and Health Sciences, Linköping University, Sweden \\ ${ }^{2}$ Department of Thoracic, Vascular Surgery, Medical and Health Sciences, Linköping University, Sweden \\ ${ }^{3}$ Department of Medical and Health Sciences, Linköping University, Sweden
}

Submission: February 27, 2019; Published: March 12, 2019

*Corresponding author: Helene Zachrisson, Department of Clinical Physiology, Medical and Health Sciences, Linköping University, SE 58185 Linköping, Sweden

\section{Abstract}

Objective: To evaluate quantitative duplex ultrasound (DUS) parameters of reflux in patients with isolated great saphenous vein insufficiency.

Methods: 20 limbs were studied. DUS derived reflux time (RT, sec), peak reflux velocity (PRV, $\mathrm{cm} / \mathrm{s}$ ) and reflux volume flow ( $\mathrm{ml} / \mathrm{min}$ ) were evaluated and related to expelled volume (EV, $\mathrm{ml})$ and half refilling time $(\mathrm{T} 50, \mathrm{sec})$ measured by water-based foot volumetry with and without compression of superficial veins.

Results: Reflux volume flow correlated significantly to all hemodynamic parameters assessed by foot volumetry, i.e., EV (p $=0.003$ ), $\Delta \mathrm{EV}$ $(p=0.006)$, T5 $(p=0.004)$ and $\Delta T 50(p=0.011)$. PRV displayed a weaker correlation to foot volumetry parameters EV $(p=0.027)$ and T50 $(\mathrm{p}=0.008)$. No significant correlation was found between RT and foot volumetry.

Conclusion: These results indicate that reflux volume flow may be a potential parameter in future attempts to quantify reflux using DUS in patients with isolated great saphenous vein insufficiency.

Keywords: Venous insufficiency; Foot volumetry; Duplex ultrasound; Pathophysiology; Anatomical distribution

\section{Introduction}

Chronic venous insufficiency is a common condition with clinical signs ranging from minor telangiectasias, varicose veins, edema to more severe stages with skin manifestations as eczema, lipodermatosclerosis and venous ulcers [1-3]. The diagnosis relies on physical examination ( $\mathrm{C}$ of the CEAP classification, "Clinical Etiology Anatomy Pathophysiology") [4] as well as noninvasive testing $[3,5]$. Duplex ultrasound (DUS) is considered to be gold standard and provides diagnostic information about the anatomical distribution of the disease $[3,6]$. A retrograde flow (reflux time, RT) of more than 0.5 seconds is generally used to define the presence of reflux [6]. However, individual RT does not seem to reflect the magnitude of reflux and the correlation between severity of disease or hemodynamic state and RT is limited [7]. Based on this it has been suggested that RT may be used for detection of reflux but other DUS derived parameters are needed for quantifying venous insufficiency $[7,8]$. Previous attempts to quantify reflux using DUS has involved peak reflux velocity $(\mathrm{m} / \mathrm{s})$, calculated reflux volume flow $(\mathrm{ml} / \mathrm{min})$ and reflux volume (ml) [7], however, the optimal method for quantifying reflux by DUS is still unclear [9]. Quantitative information of global venous hemodynamics can be derived from plethysmographic measurements such as strain gauge, photo, air as well as foot volumetry [10-12]. We have shown that it is possible to predict post-interventional outcome in Great Saphenous Vein Incompetence using strain-gauge plethysmography [10].

Foot volumetry may provide accurate information on the magnitude of global venous reflux as well as correlate to $C$ in the CEAP classification $[4,12]$. The aim of the study was to evaluate DUS derived reflux parameters in patients with isolated great saphenous vein insufficiency (GSV) compared to quantifying plethysmographic measurements using foot volumetry.

\section{Material and Methods}

46 consecutive patients referred to Department of Clinical Physiology, Linköping University Hospital for evaluation of venous insufficiency in the lower limb were evaluated according 
to the study protocol. All patients were investigated with both Duplex ultrasound (DUS) and water-based foot volumetry. Six patients presented with small saphenous vein (SSV) insufficiency. Patients with mixed and/or isolated SSV insufficiency were excluded from the study. Finally, eighteen patients with isolated great saphenous vein (GSV) insufficiency (13 women and 5 men, mean age 59 years, range 40 - 90 years), two with bilateral GSV insufficiency (20 legs) were included in the study. Demographical and clinical data (C in CEAP) [4] is presented in Table 1. The study was approved by the regional ethical review board in Linköping, Sweden, and written informed consent was provided by each participant.

Table 1: Demographical and clinical data.

\begin{tabular}{|c|c|}
\hline Patients (n) & 18 \\
\hline Limbs (n) & 20 \\
\hline Sex F/M & $13 / 5$ \\
\hline Mean age, y (range) & $59(40-90)$ \\
\hline GSV Diameter (mean \pm SE) & $4.1(0.4)$ \\
\hline C in CEAP (mean \pm SE) & $2.8(0.2)$ \\
\hline C2 & 10 \\
\hline C3 & 6 \\
\hline C4 & 3 \\
\hline C5 & 0 \\
\hline C6 & 1 \\
\hline
\end{tabular}

\section{Duplex ultrasound}

DUS examinations were performed with ACUSON S2000 system (Siemens Medical Solutions, Malvern, PA, USA) with 9 and $18 \mathrm{MHz}$ transducers. The $9 \mathrm{MHz}$ transducer was used for assessment of reflux. Patients were examined in the sitting position and superficial (saphenous veins and tributaries), perforator and deep veins (femoral, common femoral, deep femoral, popliteal, and calf veins) were scanned in both longitudinal and transverse planes. A distal manual compression was used to determine the valvular integrity. Normal veins were defined as veins with no reflux, normal reflux time (RT, duration $<0.5 \mathrm{sec}$ ), or a very short reflux area (between 2 or 3 valves). If a pathologic reflux was detected, i.e., RT > $0.5 \mathrm{sec}$, spectral Doppler measurements was performed along the vein in the longitudinal plane at $60^{\circ}$ angle. Measurements were made in the insufficient GSV at the distal thigh level. At least three measurements were conducted at each point (proximal, mid and distal part on the thigh) and the mean value was used in the calculations. The anatomical extent of reflux was carefully noted, and no perforator reflux was noted on the calf or thigh level. Spectral flow velocity and vessel diameter was measured where the vein was straight, and turbulent areas were disregarded. The magnitude of reflux was quantified in several ways. i.e., RT (sec), peak reflux velocity (PRV, $\mathrm{m} / \mathrm{s}$ ) and time average velocity (TAV, $\mathrm{m} / \mathrm{s}$ ) during the first second of reflux. The vessel lumen was considered circular and the cross-sectional area was calculated as the area of a circle $\left(A=\Pi r^{2}\right)$. Thus, reflux volume flow (ml/min) was calculated according to the following:

reflux volume flow $(\mathrm{ml} / \mathrm{min})=T A V(\mathrm{~m} / \mathrm{s}) \times A\left(\mathrm{~cm}^{2}\right) \times 60$.

Hence, three DUS derived parameters were studied: RT (sec), $\mathrm{PRV}(\mathrm{m} / \mathrm{s})$ and reflux volume flow $(\mathrm{ml} / \mathrm{min})$.

\section{Foot volumetry}

Global venous hemodynamics were evaluated with water-based foot volumetry [13]. The foot volumeter consisted of an open, water-filled box, which enabled measurements of volume changes during exercise [13]. Patients performed 20 knee bends at the rate of one every two seconds, and after the exercise phase was completed the patients remained completely still during the refilling phase. Expelled volume (EV, $\mathrm{ml})$, and the time taken in seconds for $50 \%\left(\mathrm{~T}_{50}\right)$ of the venous volume to be refilled was evaluated both with and without compression of superficial veins either above or below knee. A $10 \mathrm{~cm}$ wide tourniquet was inflated to $60 \mathrm{mmHg}$ to achieve superficial compression.

\section{Statistics}

Values are expressed as mean \pm SD unless otherwise stated. Spearman correlation coefficient (rho) were calculated for non-parametric linear association between different DUS parameters and foot volumetry measurements. $p$-values $<0.05$ were considered significant. Statistical analyses were carried out using SPSS 24.0 for Windows (Armonk, NY: IBM Corp.).

\section{Results}

Isolated great saphenous vein (GSV) insufficiency was detected in 20 legs. DUS measurements displayed a mean vessel diameter of $4.2 \pm 2.0 \mathrm{~mm}$. RT was $3.3 \pm 1.3 \mathrm{sec}, \mathrm{PRV} 45 \pm 19 \mathrm{~cm} / \mathrm{s}$, TAV $13.0 \pm 6.9 \mathrm{~cm} / \mathrm{s}$, and calculated reflux volume flow $128 \pm 114 \mathrm{ml} /$ min. EV was $13.6 \pm 7.9 \mathrm{ml}$, and $\mathrm{T}_{50}$ was $7.3 \pm 6.4 \mathrm{sec}$ during foot volumetry without superficial compression. $\mathrm{EV}$ increased to 20.1 $\pm 8.1 \mathrm{ml}$, and $\mathrm{T}_{50}$ increased to $13.0 \pm 6.2 \mathrm{sec}$ after superficial occlusion. The calculated difference between foot volumetry measurements with and without superficial occlusion, i.e., $\Delta \mathrm{EV}$ and $\Delta \mathrm{T}_{50}$ were $6.5 \pm 9.6 \mathrm{ml}$ and $5.8 \pm 5.0 \mathrm{sec}$ respectively.

Table 2 shows the correlation between different DUS derived parameters and foot volumetry measurements. Reflux volume flow correlated negatively with foot volumetry parameters EV (rho $=-0.626, p=0.003$ ) and $\mathrm{T}_{50}$ (rho $=-0.613, p=0.004$ ). Reflux volume flow correlated positively with $\Delta \mathrm{EV}$ (rho $=0.588, p$ $=0.006)$ and $\Delta \mathrm{T}_{50}$ (rho $\left.=0.554, p=0.011\right)$. A negative correlation was also found between PRV and EV (rho $=-0.493, p=0.027$ ) as well with $\mathrm{T}_{50}$ (rho $\left.=-0.574, p=0.008\right)$. No correlation was detected between RT and foot volumetry parameters. Figure 1 shows reflux volume flow divided into three groups, mild refux $(<30 \mathrm{ml} / \mathrm{min})$, moderate reflux $(30-100 \mathrm{ml} / \mathrm{min})$ and severe reflux $(>100 \mathrm{ml} /$ $\mathrm{min}$ ). This classification demonstrated a correlation with EV (rho $=-0.519, p=0.019), \Delta \mathrm{EV}(\mathrm{rho}=0.504, p=0.023), \mathrm{T}_{50}(\mathrm{rho}=-0.589$, $p=0.006)$ and $\Delta \mathrm{T}_{50}($ rho $=0.460, p=0.041)$. 
Table 2: Correlation between duplex ultrasound derived parameters and foot volumetry.

$\mathrm{EV}$, expelled volume; $\Delta \mathrm{EV}$, difference in $\mathrm{EV}$ between foot volumetry with and without superficial occlusion; $\mathrm{T}_{50} ;$ half refilling time; $\Delta \mathrm{T}_{50}$, difference in $T_{50}$ between foot volumetry with and without superficial occlusion

\begin{tabular}{|c|c|c|c|}
\hline Duplex Ultrasound Parameters & Foot Volumetry Parameters & $\boldsymbol{P}$ & Spearman Correlation Coefficients (rho) \\
\hline \multirow{3}{*}{ Reflux time (sec) vs } & $\mathrm{EV}$ & 0.229 & 0.281 \\
\cline { 2 - 4 } & $\Delta \mathrm{EV}$ & 0.903 & -0.029 \\
\cline { 2 - 4 } & $\mathrm{T}_{50}$ & 0.104 & 0.374 \\
\cline { 2 - 4 } & $\Delta \mathrm{T}_{50}$ & 0.545 & -0.144 \\
\hline \multirow{3}{*}{ Peak reflux velocity (cm/s) vs } & $\mathrm{EV}$ & 0.027 & -0.493 \\
\cline { 2 - 4 } & $\Delta \mathrm{EV}$ & 0.096 & -0.574 \\
\cline { 2 - 4 } & $\mathrm{T}_{50}$ & 0.008 & 0.296 \\
\hline \multirow{3}{*}{ Reflux volume flow (ml/min) vs } & $\Delta \mathrm{T}_{50}$ & 0.252 & -0.626 \\
\cline { 2 - 4 } & $\mathrm{EV}$ & 0.003 & 0.588 \\
\cline { 2 - 4 } & $\Delta \mathrm{EV}$ & 0.006 & -0.613 \\
\hline
\end{tabular}

A

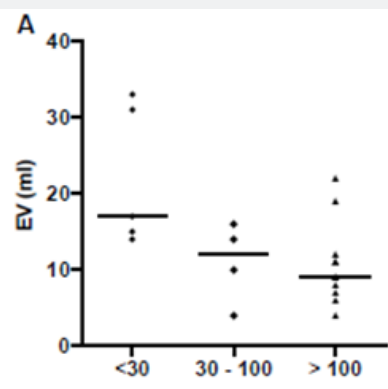

Reflux volume flow $(\mathrm{ml} / \mathrm{min})$

C

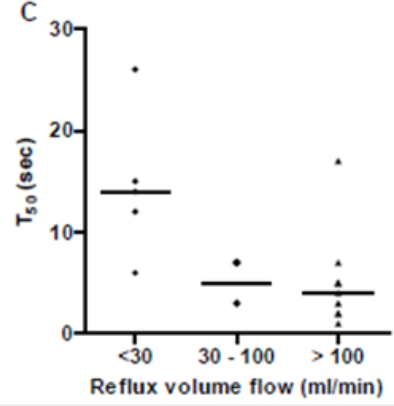

B

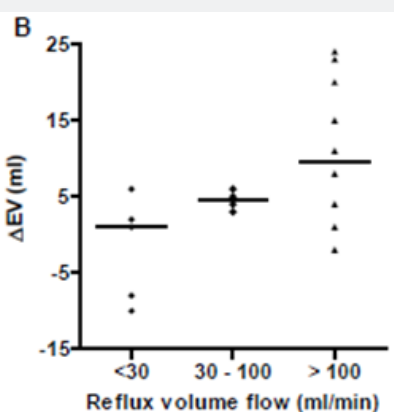

D

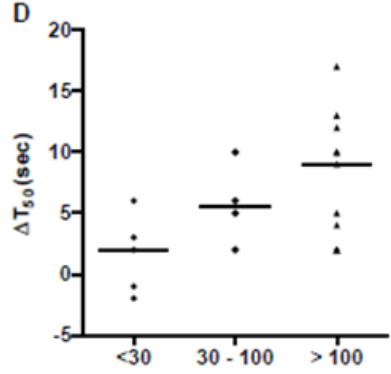

Figure 1: Semi quantification of superficial venous reflux according to volume flow and its correlation to foot volumetry measurements. Reflux volume flow divided into mild reflux, moderate reflux and severe reflux correlated with $E V(r=-0.519, p=0.019, A), \Delta E V(r=0.504$, $p=0.023, B) T_{50},(r=-0.589, p=0.006, C)$ and $\Delta T_{50}(r=0.460, p=0.041, D)$. EV, expelled volume; $\Delta E V$, difference in EV between foot volumetry with and without superficial occlusion; T50; half refilling time; $\Delta T_{50}$, difference in $T_{50}$ between foot volumetry with and without superficial occlusion. Bars represent the median level.

\section{Discussion}

This study was designed to evaluate different DUS parameters describing reflux in patients with isolated GSV and relate them to alterations in global venous hemodynamics based on water-based foot volumetry. The main findings were that particularly DUS derived reflux volume flow significantly related to global hemodynamic measurements during foot volumetry. Thus, the present study supports previous findings that reflux volume flow may be a potential parameter in future attempts to quantify reflux using DUS in patients with isolated GSV insufficiency.

DUS is a well-established method in the diagnosis of CVI and is able to measure several reflux components [6]. There has been numerous attempts to use one or more of these components as indexes for global reflux severity, although the most useful and reliable parameter for quantification of superficial reflux is still under debate. On the other hand, dynamic measurements of volume 
changes with plethysmographic methods may provide accurate quantitative information about whole limb venous haemodynamics and abnormalities in the reflux phase [10-12]. Foot volumetry was used in this study and previous findings suggest that it may provide accurate information on the magnitude of global venous reflux as well as correlate both to the clinical severity of the disease and the ambulatory venous pressure $[12,14]$. A further advantage with foot volumetry is that the method uses a dynamic and quite heavy situation, kneeling, which is supposed to simulate walking. In order to investigate the relation between DUS parameters and global reflux occlusion of the superficial system was accomplished with a tourniquet to evaluate the magnitude of superficial reflux in each patient.

RT was initially viewed as potential quantitative parameter and earlier studies found that patients with ulceration demonstrated a longer total mean RT than those without ulcers [15]. In the present study, no association was found between RT and any parameter of global reflux derived from foot volumetry. This is consistent with more recent studies who have shown RT to be a poor quantifier of individual reflux as well as an inadequate parameter to discriminate between disease severity $[7,8,16]$. Taken together, RT may primary be viewed as a qualitative parameter. Other parameters, such as, PRV has been found to provide a better quantitative evaluation compared to RT, e.g., $\mathrm{PRV}>30 \mathrm{~cm} / \mathrm{s}$ has in previous studies been suggested as a risk factor for venous ulceration and patients with skin changes presented with significant higher PRV $[17,18]$. In line with this we found that PRV was associated to foot volumetric parameters $\mathrm{EV}$ as well as $\mathrm{T}_{50}$.

The parameters derived from DUS that showed best correlation with foot volumetry measurements was volume flow. Reflux volume flow was related to $\mathrm{EV}$ and $\mathrm{T}_{50}$ at baseline as well as to changes in global reflux after occlusion of the superficial veins evaluated by $\Delta \mathrm{EV}$ and $\Delta \mathrm{T}_{50}$. Assessment of retrograde flow volume has previously shown that reflux greater than $10 \mathrm{ml} / \mathrm{sec}$ is related to a high incidence of skin changes [19] and volume flow also seems to correlate with the hemodynamic state measured with air plethysmography $[7,8]$. Although the association to clinical severity is still uncertain [7] our result suggest that reflux volume flow may provide a reflection of the magnitude of venous incompetence. In an attempt to classify the results of reflux volume flow in mild, moderate and severe reflux a correlation was found with all volumetric parameters, i.e., $\mathrm{EV}, \Delta \mathrm{EV}, \mathrm{T}_{50}$ and $\Delta \mathrm{T}_{50}$, when volume flow was divided into $<30 \mathrm{ml} / \mathrm{min}$ (mild), $30-100 \mathrm{ml} / \mathrm{min}$ (moderate) and $>100 \mathrm{ml} / \mathrm{min}$ (severe). This characterization seems to agree with previous studies showing that normal values of EV and $\mathrm{T}_{50}$ appears to center around $16 \mathrm{ml}$ and $20 \mathrm{sec}$ respectively, although higher age may be associated with lower EV and $\mathrm{T}_{50}[14]$. Based on the proposed groups, a gradual decrease in both EV and $\mathrm{T}_{50}$ can be seen as reflux volume flow was classified as moderate or severe. Correspondingly, no obvious improvement at group level was found in $\Delta \mathrm{EV}$ and $\Delta \mathrm{T}_{50}$ when volume flow was classified as mild reflux. However, in both moderate and severe reflux, $\Delta \mathrm{EV}$ and $\Delta \mathrm{T}_{50}$ displayed a gradual improvement. This kind of semi classifi- cation may be helpful in early diagnostics as well as postoperative follow up.

The purpose of this study was to compare different segmental DUS derived parameters in order to understand which of these parameters best reflected global hemodynamic changes in patients with GSV insufficiency. Based on this, reflux volume flow seemed to provide the most reliable results. Nonetheless, it should be noticed that the information provided by DUS cannot replace the global evaluation derived plethysmografic investigations, especially in patients with a more complex disease, such as, mixed deep and superficial incompetence.

\section{Limitations}

The present material is small and further studies are also needed to evaluate the suggested classification in relation to other parameters of global venous reflux as well as the relation between clinical severity and both DUS and plethysmographic data.

We recently developed for selective occlusion of superficial veins validated by ascending phlebology [10]. and this model must be evaluated in larger studies. Thus, larger populations need to be performed to assess DUS derived reflux volume flow with other parameters of global venous reflux and its correlation to clinical severity.

\section{Conclusion}

In the present study reflux volume flow appeared to best reflect the magnitude of venous incompetence. Further, a semi quantification derived from DUS investigation in individual vein segments is suggested by using limits for mild reflux $<30 \mathrm{ml} / \mathrm{min}$, moderate reflux $30-100 \mathrm{ml} / \mathrm{min}$ and severe reflux $>100 \mathrm{ml} / \mathrm{min}$. Further and larger studies combining DUS and plethysmographic methods are needed to confirm the results as well as to evaluate the possible benefits of quantify reflux with DUS in the clinical practice.

\section{Funding Statement}

This research was funded by ALF Grants, Region Ostergotland [LIO-700491].

\section{References}

1. Evans CJ, Fowkes FG, Ruckley CV, Lee AJ (1999) Prevalence of varicose veins and chronic venous insufficiency in men and women in the general population: Edinburgh Vein Study. J Epidemiol Community Health 53(3): 149-153.

2. Maurins U, Hoffmann BH, Losch C, Jockel KH, Rabe E, et al. (2008) Distribution and prevalence of reflux in the superficial and deep venous system in the general population--results from the Bonn Vein Study, Germany. J Vasc Surg 48(3): 680-687.

3. Wittens C, Davies AH, Baekgaard N, Broholm R, Cavezzi A, et al. (2015) Editor's Choice - Management of Chronic Venous Disease: Clinical Practice Guidelines of the European Society for Vascular Surgery (ESVS). Eur J Vasc Endovasc Surg 49(6): 678-737.

4. Vasquez MA, Rabe E, McLafferty RB, Shortell CK, Marston WA, et al. (2010) Revision of the venous clinical severity score: venous outcomes consensus statement: special communication of the American Venous 
Forum Ad Hoc Outcomes Working Group. J Vasc Surg 52(5): 13871396.

5. Gloviczki P, Comerota AJ, Dalsing MC, Eklof BG, Gillespie DL, et al. (2011) The care of patients with varicose veins and associated chronic venous diseases: clinical practice guidelines of the Society for Vascular Surgery and the American Venous Forum. J Vasc Surg 53(5 Suppl): $2 \mathrm{~S}-48 \mathrm{~S}$.

6. Eberhardt RT, Raffetto JD (2014) Chronic Venous Insufficiency Circulation 130(4): 333-346

7. Neglen P, Egger JF, Olivier J, Raju S (2004) Hemodynamic and clinical impact of ultrasound-derived venous reflux parameters. J Vasc Surg 40(2): 303-310

8. Yamaki T, Nozaki M, Sakurai H, Takeuchi M, Kono T, et al. (2007) Quantification of venous reflux parameters using duplex scanning and air plethysmography. Phlebology 22(1): 20-28.

9. Nicolaides A, Clark H, Labropoulos N, Geroulakos G, Lugli M, et al (2014) Quantitation of reflux and outflow obstruction in patients with CVD and correlation with clinical severity. Int Angiol 33(3): 275-281.

10. Nelzen PO, Skoog J, Lassvik C, Lanne T, Zachrisson H (2016) Prediction of Post-interventional Outcome in Great Saphenous Vein Incompetence: The Role of Venous Plethysmography with Selective Superficial Vein Occlusion. Eur J Vasc Endovasc Surg 52(3): 377-384.

11. Criado E, Farber MA, Marston WA, Daniel PF, Burnham CB, et al. (1998) The role of air plethysmography in the diagnosis of chronic venous insufficiency. J Vasc Surg 27(4): 660-670.

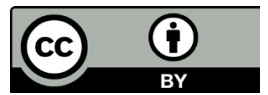

This work is licensed under Creative Commons Attribution 4.0 License DOI: 10.19080/JOJCS.2019.10.555776
12. Danielsson G, Norgren L, Jungbeck C, Peterson K (2003) Global venous function correlates better than duplex derived reflux to clinical class in the evaluation of chronic venous disease. Int Angiol 22(2): 177-181.

13. Norgren L (1974) Functional evaluation of chronic venous insufficiency by foot volumetry. Acta Chir Scand Suppl 444: 1-48.

14. Nicolaides AN, Cardiovascular Disease E, Research T, European Society of Vascular Surgery, The International Angiology Scientific Activity Congress Organization, et al. (2000) Investigation of chronic venous insufficiency: A consensus statement (France, March 5-9, 1997). Circulation 102(20): E126-E163.

15. Weingarten MS, Branas CC, Czeredarczuk M, Schmidt JD, Wolferth CC (1993) Distribution and quantification of venous reflux in lower extremity chronic venous stasis disease with duplex scanning. J Vasc Surg 18(5): 753-759.

16. Konoeda H, Yamaki T, Hamahata A, Ochi M, Sakurai H (2014) Quantification of superficial venous reflux by duplex ultrasound-role of reflux velocity in the assessment the clinical stage of chronic venous insufficiency. Ann Vasc Dis 7(4): 376-382.

17. Yamaki T, Nozaki M, Sasaki K (1998) Color duplex ultrasound in the assessment of primary venous leg ulceration. Dermatol Surg 24(10): 1124-1128.

18. Danielsson G, Eklof B, Grandinetti A, Lurie F, Kistner RL (2003) Deep axial reflux, an important contributor to skin changes or ulcer in chronic venous disease. J Vasc Surg 38(6): 1336-1341.

19. Vasdekis SN, Clarke GH, Nicolaides AN (1989) Quantification of venous reflux by means of duplex scanning. J Vasc Surg 10(6): 670-677.

\section{Your next submission with Juniper Publishers} will reach you the below assets

- Quality Editorial service

- Swift Peer Review

- Reprints availability

- E-prints Service

- Manuscript Podcast for convenient understanding

- Global attainment for your research

- Manuscript accessibility in different formats

( Pdf, E-pub, Full Text, Audio)

- Unceasing customer service

Track the below URL for one-step submission https://juniperpublishers.com/online-submission.php 